\title{
Health Information Technology and Caregiver Interaction: Building Healthy Ecosystems
}

\author{
Nabil Georges Badr ${ }^{1}$, Maddalena Sorrentino², Marco De Marco ${ }^{3}$ \\ ${ }^{1}$ Grenoble Graduate School of Business, Grenoble, France \\ nabil.badrealumni.grenoble-em.com \\ ${ }^{2}$ Università degli Studi di Milano, Milan, Italy \\ maddalena.sorrentino@unimi.it \\ ${ }^{3}$ Università Telematica Internazionale Uninettuno, Rome, Italy \\ marco.demarco@uninettunouniversity. net
}

\begin{abstract}
This qualitative study explores the widely recognized role of the informal caregivers (ICGs) as key co-producers in the delivery of effective and sustainable healthcare systems. The central argument is that to enhance the quality of care in non-clinical settings and the healthcare ecosystem as a whole, developers of Health Information Technology (HIT) need to harness the knowledge and experiences of the ICGs to better align their products to practice. The paper has two aims: to improve the understandability of informal caregivers' role in non-traditional healthcare settings, and to identify and formulate valuable guidelines for the development of "fit for use" HIT solutions that acknowledge the needs of the ICGs.
\end{abstract}

Keywords: informal caregivers, health IT, co-production, HIT development guiding principles

\section{Introduction}

Health Information Technology is the application of information technology to health and healthcare. The fact that Health Information Technology ('HIT') brings together the management and computerization of health information with a wide range of stakeholders means it has far-reaching effects on the delivery and consumption of healthcare and health-related services [1: iv]. In this paper, HIT is defined as the use of information and communication technology (ICT) by formal (i.e., professional) and informal caregivers to deliver healthcare services in non-traditional settings. Basically, caregivers would combine the use of social media, collaborative platforms, online portals, bedside terminals, assistive technologies, handhelds, electronics, and electronic medical records into "effective means of accessing, communicating and storing information to improve patient care and population health, and reduce healthcare expenditures" [2: 476, 3, 4].

The sustained care of informal caregivers (ICGs) could enable people with chronic diseases, e.g., cancer [5], AIDS [6], Alzheimer's [7], stroke [8], Severe Multiple Sclerosis [9], and certainly the aging [10], to be assisted by family members either at the 
hospital or at home [11]. Nevertheless, to provide an effective care package, healthcare providers who enlist informal caregivers as active patient care partners [12] need to pay careful attention to the interactions between the ICGs, the healthcare professionals and the patients [13]. HIT has done much to make the informal caregivers part of healthcare service delivery ecosystems [14] but the evidence so far suggests that, overall, it is not enough to improve outcomes across the care continuum $[2,15]$. Prior studies have demonstrated significant advances in knowledge but uncertain improvements in skills [16] - in particular, in the training of disease management planning. The attitude of the healthcare provider to the ICG as a user of HIT is often the result of a mutual misunderstanding of needs $[17,18]$. On the other hand, the perception of the ICGs and care recipients is that they are at the mercy of the healthcare professionals.

\section{- Motivation}

The difference between an informal caregiver (or family carer or caregiver, informal carer or care provider or caregiver) and a healthcare professional (e.g. clinical staff, nurse, and physician) is that the former is usually a family member, a close member of the patient's societal context, or a non-clinical social worker. ICGs operate as patient's advocates providing a source of continuity of care for their care recipient during their transitions through care settings. They also perform the functions of system navigators (who locate, evaluate and integrate relevant knowledge and information on behalf of the care recipient); or gatekeepers of support and services (assist the care recipient in the navigation of the often complex healthcare system); and coordinators of care (scheduling medical appointments and coordinating care services) [21].

The use of HIT by informal caregivers raises crucial issues for service providers. Central among these is the need for the latter to work effectively with the former [1, 2]: 'understanding caregivers' needs, their varied experiences and the complex interactions between caregivers, healthcare professionals and patient is important" [1: 154]. Hence, to fully comprehend what is required of this type of HIT it is vital is to analyze the practical everyday needs of the ICGs and their role as boundary spanners. "Significant developments in public sector services, where open standards and architecture are facilitating disintegration of services and their recombination around what has been termed service ecosystems" have yet to consider the growing role of ICGs [19: 136]. Hence, the inspiration for our research: What insights can we glean from the experiences of the ICGs, and how could these translate into some basic guidelines for the design of more tailored HIT applications?

The contribution of the qualitative analysis followed in this paper is twofold. It first seeks to consolidate our current understanding of the role of HIT in healthcare ecosystems with a review of the relevant literature. It then builds on the knowledge of the authors to elaborate a set of principles that factors in the ICG interaction to identify and formulate basic guidelines meant to productively inform HIT development. 


\section{Approach}

Health information technology (HIT) is an umbrella-term that refers to a set of computer systems, devices and interfaces used in health management and healthcare. It supports the exchange of health information between patients, carers, consumers, providers, payers, and quality monitors, in order to improve the quality of care. [17]. Vargo and Lusch [20] define HIT ecosystems as "spatial and temporal structures of largely loosely coupled, value-proposing social and economic actors interacting through institutions, technology, and language to co-produce service offerings, engage in mutual service provision, and to co-create value".

This preliminary-descriptive study explores a set of focal characteristics of a HIT ecosystem, using - as the basic units of analysis - papers and statements that show the needs of the ICGs and their interaction with formal and informal providers who cooperate and co-ordinate their activities to deliver tailor-made care.

In light of the emerging nature of these notions, a qualitative approach was taken. The research path consisted of three basic steps.

The first step was to map the relevant literature on Information Systems, Healthcare Management Informatics, and Service Management to take stock of the current state of the research and to gain insights from the evidence presented so far. We searched electronic databases, including EBSCO, Scopus and Web of Science. The primary goal was to screen for papers focused on the use of technology for caregiver interaction, scanning for the types of software, interfaces and devices that facilitate interaction practices between the caregivers and the other stakeholders of the networked service ecosystem. We conducted a search for peer-reviewed publications written in the English language ["ICT" OR "Information Technology" OR "Health Technology" OR "Health Information Technology"] AND "Caregiver Interaction". After removing duplicates, references were screened on title and abstract and then on full text. A total of 68 articles were read in full, 47 of which were selected for review due to their depth analysis of caregiver needs [5, 16, 39, 41, 44] and their relevance to the research goals.

The second step was to perform a textual analysis. Each researcher applied their personal store of knowledge and experience to identify and select the most relevant parts for the purpose of this study, then independently codified each "meaning unit" (i.e., that portion of the text associated with an identifiable theme or issue) [22]. Scientific evidence was categorized according to the Dialogue, Access, Risk, and Transparency through the lens of the ('DART') model of interaction developed by Prahalad and Ramaswamy [23] (Section 3) and coded into Key Concepts (Section 4 ). DART assumes a service dominant logic, and takes into account the service ecosystem. The 'blocks (or pillars) of interactions' identified by the original DART model encompass two types of actors: "the firm" and "the consumer". The fact that dialogue, access, risk, and transparency are key variables in the patient's experiential sphere thus makes the DART model [23] a good analytical fit for the interactions between the service provider and the ICG $[13,24]$. The coding results and interpretations were shared and discussed, focusing on cases in which the same meaning unit could be slotted into several categories. The key pieces of evidence were organized by one of the researchers via an iterative process. 
The third and final part of the study was to formulate a set of basic principles that factor in ICG interaction as a preliminary response to our research question (Section 4, Table. 1). The studies reviewed inform that the DART approach shifts the focus from the features and technicalities to the implications of the multiple experiences in which ICGs are engaged. In other words, the adoption of a service logic [4] enables the charting of an ontological path [25] to connect each DART pillar of interaction. The insights generated were then translated into some basic principles (or guidelines) to help the HIT designers and developers better align their products to the needs of the ICGs.

\section{Applying the DART lens: pillars of interaction}

Previous research work has recognized informal caregivers as patient advocates, gatekeepers of support and services, and coordinators of care (Table 1). Sorrentino et al. [21] qualified the service roles of informal caregivers under the lens of building blocks of interaction.

Table 1. The Dialogue, Access, Risk, and Transparency (DART) map and the intersecting roles of informal caregivers [21]

\begin{tabular}{|c|c|c|c|}
\hline & Patient's Advocate & $\begin{array}{l}\text { System Navigator } \\
\text { \& Gatekeeper }\end{array}$ & Coordinator of Care \\
\hline D & $\begin{array}{l}\text { Dialog and information } \\
\text { exchange between caregiv- } \\
\text { ers }\end{array}$ & $\begin{array}{l}\text { Understanding of needs } \\
\text { between formal and infor- } \\
\text { mal caregivers }\end{array}$ & $\begin{array}{l}\text { Coordination supported by } \\
\text { relationships of shared } \\
\text { goals/shared knowledge }\end{array}$ \\
\hline $\mathbf{A}$ & $\begin{array}{l}\text { Data access issues can } \\
\text { impede the effectiveness of } \\
\text { informal caregivers }\end{array}$ & $\begin{array}{l}\text { Access to multiple sources } \\
\text { enables the exchange of } \\
\text { information on patient } \\
\text { condition }\end{array}$ & $\begin{array}{l}\text { Technological access to } \\
\text { useful data optimizes the } \\
\text { coordination of care }\end{array}$ \\
\hline $\mathbf{R}$ & $\begin{array}{l}\text { Problem-solving approach } \\
\text { to reduce patient health } \\
\text { risks }\end{array}$ & $\begin{array}{l}\text { Possible induced risk to the } \\
\text { informal caregiver }\end{array}$ & $\begin{array}{l}\text { Informal caregiver prepar- } \\
\text { edness }\end{array}$ \\
\hline $\mathbf{T}$ & $\begin{array}{l}\text { Care-recipient spokesper- } \\
\text { sons and intermediaries } \\
\text { with service providers }\end{array}$ & $\begin{array}{l}\text { Transparency of infor- } \\
\text { mation flow impeded by } \\
\text { fears over security and loss } \\
\text { of privacy }\end{array}$ & $\begin{array}{l}\text { Improved disease manage- } \\
\text { ment through patient en- } \\
\text { gagement and family care- } \\
\text { giver assistance }\end{array}$ \\
\hline
\end{tabular}

The authors of this paper find it interesting to apply this conceptual approach to mapping the role of the informal caregivers to contextual implications of using HIT. It then extends prior research and offers a crisper look into how HIT could enable informal providers in each of their identified roles in the health service ecosystem.

\section{- $\quad$ Enhanced Dialog between Formal and Informal Caregivers (D)}

ICGs use HIT tools to reinforce their communication within the healthcare organization [26]. The literature supports the consistent incorporation of novel ideas for patients and ICGs to manage their own conditions and to foster communication among the circle of care [27]. Some solutions include secure messaging for communication 
among the patient care team, putting the patient in control of his/her health data privacy [28]. ICGs place critical value on continuous communication with primary care providers, especially to receive recommendations, guidance and endorsement to sources of caregiving information in the early stages of the caregiving journey [12]. Whether patients or their informal carers actually make use of and benefit from available HIT applications still hinges upon the attitude of their professional care provider towards such sources of information [17]. Nevertheless, the attitude of the professional care provider towards HIT use by informal caregiver may affect the understanding of needs between formal and informal caregivers. Hence, workflow clarity is a vital component for role definition and understanding between formal and informal caregivers: the potential for tension arises as the use of technology might result in a successful outcome for one party (professional caregiver) but not necessarily for another (family carers) [29]. This is a critical requirement for the coordination of care between formal and informal caregivers, which is supported by relationships of shared goals and shared knowledge [30].

\section{- $\quad$ Access to Data by Informal Caregivers (A)}

HIT provides access to useful data known to optimize the coordination of care. Online availability of data sources have shortened physical distance [31], consolidated health information about the patient, and provided an opportunity to maintain up-to-date information about care professionals and care-related goals [28]. Access to multiple sources enables the exchange of information on patient condition. Subsequently, the ability to gather data and analyse it into essential feedback for monitoring and alerting (e.g. breathing monitors in premature infants), diagnosis and important treatment information known to improve the interaction between caregivers ('CGs') [32]. This enhances caregiver knowledge base but not necessarily caregiver skills, which still requires training on specific disease management plans. Moreover, extant pressure of technology usage skills may introduce data entry errors due to barriers of computer illiteracy. Computer illiteracy can be a barrier to online services [33]; however, access to online assisted literacy resources require little training if they are well-designed [34]. Such information may include the understanding of the course of the disease, the importance of caring for self, finding respite and long-distance care provision [35]. ICGs expect HIT tools to be easy to use whereby navigation ought to provide access to information quickly and easily [36]. The use of memory aids, visual aids, access to training programs [37]. Examples could be used with text and displays that are easy to read [38].

\section{- $\quad$ Patient Risk Mitigation and Lessening the Burden on ICG (R)}

Extant pressure of technology usage skills may introduce data entry errors due to barriers of computer illiteracy [43]. Risks of patient health and privacy issues often offset efforts to increase caregiver preparedness [36]. Education on patient's health risks, ought to be imbedded in portals $[20,36,57]$ with guidance on treatment provides potential improvement of possible induced risk to the informal caregiver [29, 43]. Technology-based interventions can reduce the caregiving burden, depression, 
anxiety and stress, and improve the ICG's coping ability [41], but not without unforeseen additional pressures, such as checking equipment, interpreting movements and having additional care responsibilities [29]. Assistive technologies have been proposed to overcome elderly problems such as fall risk, chronic disease, dementia, social isolation and poor medication management. Assistive technologies help reduce the burden among ICGs of older adults [39]; these technologies were also found to reduce anxiety in informal carers of people with dementia [40]. Components of HIT such as computerized prescription tools for instance, are clear examples of how risk reduction occurs in the case of a patients' and the informal caregiver are reminded of the correct intake of the prescribed medicine. The benefits of HIT components, such as computerized prescription tools and medication dosage calculation devices which tell the ICG the correct intake of their care recipients' prescribed medicine, include a reduction in the risk of error [43] and higher rates of prescription adherence. However, for this to be effective, an already functioning adherence program needs to be in place [44] to ensure the ICG's preparedness. Care recipients are set up with health monitoring technologies at home, growing the ICG support base of non-family members to include close family members, thus enriching the ICG's social and behavioral support [26]. While monitoring [through technologies] may provide peace of mind for carers, it may be perceived as invasion of privacy in some settings [29]. Users must be able to deactivate sensors and data transmission whenever they want [42].

\section{- Transparency of Information Flow between Formal and Informal CGs (T)}

The computerization of patient health records and online access to readily available data enables the working ICGs to access information, receive psychosocial support from the professional counterpart and benefit from potential learning opportunities [45], but also brings into play the question of transparency. The main concerns of the formal CGs center on security and patient privacy and the ethics of processing and transmitting sensitive data outside the professional sphere; not only can this undermine the completeness, and hence usefulness, of the data transmitted to the ICG, but also can make the formal caregivers reluctant to share electronic data files with them [46]. Moreover, the ICG must be informed of the HIT tool's specific purpose and be allowed to gain a certain familiarity with it [36]. Adequate training and encouragement from others are essential in motivating family carers to use technology-based support services (ibidem). Those services (online support, helpdesk, etc.) can be valuable for older family carers in rural areas, for instance, where adopting new technology could help them and their care recipients regain social inclusion [47]. The language used must be familiar to the ICG, with interfaces that incorporate readily available lexicons written in simple, easy to follow terms [36]. Transparency of information flow is often impeded by fears over security and loss of privacy. A foundational concept of information sharing in healthcare is to avail patient health and biography information only to the authorized providers of care as concerns of confidentiality may be seen to outweigh benefits of quality of care [45]. Patient engagement and family caregiver access to portals may improve self-regulated disease management. The direct participation of the informal caregiver in the health IT ecosystem facilitates 
the continuity of care. This imposes a strong reliance on the level of use of the formal caregivers of the technology in order to record useable patient data.

\section{Framing HIT Guiding Principles for CG Interaction}

We applied a coding technique to the literature reviewed [48] that allowed for the emergence of open codes [49]. This generated key concepts that constitute the component of guiding principles of caregiver interaction for HIT (Table 2).

Table 2: Literature review coding results

\begin{tabular}{|c|c|c|}
\hline DART & Key Concepts/Principles & $\begin{array}{c}\text { Caregiver Needs and Interaction } \\
\text { (Exemplary meaning units from the literature review) }\end{array}$ \\
\hline 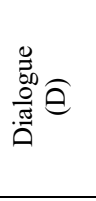 & $\begin{array}{l}\text { Reinforce dialog, commu- } \\
\text { nication and coordination }\end{array}$ & $\begin{array}{l}\text { ICGs use HIT tools to reinforce their communication within the } \\
\text { healthcare organization [26]. ICGs use HIT tools to foster } \\
\text { communication among the circle of care [27]. ICGs place } \\
\text { critical value on continuous communication with primary care } \\
\text { providers [12], and coordination of care between formal and } \\
\text { informal caregivers [30]. }\end{array}$ \\
\hline \multirow[t]{2}{*}{ 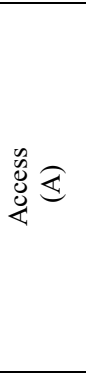 } & $\begin{array}{l}\text { Provide access to data on } \\
\text { the patient, understanding } \\
\text { the course of disease and } \\
\text { knowledge of treatment } \\
\text { information }\end{array}$ & $\begin{array}{l}\text { Online availability of data sources shortens the physical dis- } \\
\text { tance and improves CG effectiveness [31]. Access to consoli- } \\
\text { dated health information about the patient, care professionals } \\
\text { and care-related goals [28]. Knowledge of important treatment } \\
\text { information improves interaction between caregivers [32]. } \\
\text { Understanding of the course of the disease, the importance of } \\
\text { caring for self, finding respite and remote care provision [35]. }\end{array}$ \\
\hline & $\begin{array}{l}\text { Provide access to HIT } \\
\text { tools that are easy to use }\end{array}$ & $\begin{array}{l}\text { ICGs expect HIT tools to be easy to use whereby navigation } \\
\text { ought to provide access to information quickly and easily [36]. } \\
\text { Use of memory aids, visual aids, training programs [37], easy- } \\
\text { to-read displays [38]. }\end{array}$ \\
\hline \multirow{3}{*}{ 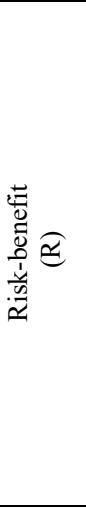 } & $\begin{array}{l}\text { Reduce the burden of ICT } \\
\text { literacy on the caregiver } \\
\text { to reduce chances of error }\end{array}$ & $\begin{array}{l}\text { Well-designed assisted literacy resources require little training } \\
\text { [34]. Easy access to disease information [20], [36], [57] and to } \\
\text { online support, helpdesk, etc. [47] to lessen risk of errors [43]. } \\
\text { Minimize pressure on ICG of checking equipment interpreting } \\
\text { movements and having additional care responsibilities [29]. } \\
\text { Use of familiar language, and easy-to-understand interfaces } \\
\text { [36]. Reduce risk to care recipient (e.g. prescription errors) by } \\
\text { providing tools for prescription aid [43]. }\end{array}$ \\
\hline & $\begin{array}{l}\text { Provide features to reduce } \\
\text { CGs anxiety }\end{array}$ & $\begin{array}{l}\text { Provide features to reduce ICG anxiety [40] and improve ICG's } \\
\text { coping ability [39] [41], i.e. ICGs must understand the intent of } \\
\text { the software (or device) and gain familiarity with it [36]. }\end{array}$ \\
\hline & $\begin{array}{l}\text { Provide appropriate secu- } \\
\text { rity and privacy }\end{array}$ & $\begin{array}{l}\text { Technological data monitoring may be perceived as invasion of } \\
\text { privacy [29]. Users must be able to deactivate their own data } \\
\text { transmission whenever they want [42]. Overcoming significant } \\
\text { challenges of security and privacy of sensitive data [46]. }\end{array}$ \\
\hline 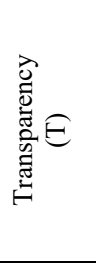 & $\begin{array}{l}\text { Provide features for trans- } \\
\text { parent information flow } \\
\text { between formal and in- } \\
\text { formal CGs }\end{array}$ & $\begin{array}{l}\text { Provide secure messaging for communication among the pa- } \\
\text { tient care team [28]. Enable working ICGs to access infor- } \\
\text { mation, receive support from professional CG and network } \\
\text { transparently [45]. Adequate training and encouragement to } \\
\text { motivate family carers to use technology-based support ser- } \\
\text { vices [36]. Workflow clarity is a vital component for role } \\
\text { definition and understanding for transparency in information } \\
\text { flow between formal and informal caregivers [29] }\end{array}$ \\
\hline
\end{tabular}




\begin{tabular}{|l|l|l|}
\hline $\begin{array}{l}\text { Provide features for pa- } \\
\text { tient engagement to re- } \\
\text { duce challenges of securi- } \\
\text { ty and privacy. }\end{array}$ & $\begin{array}{l}\text { Putting the patient in control of their health data privacy [28]. } \\
\text { Patient engagement practices, enabled by secured portals, bring } \\
\text { the control of who can have access to patient data [56]. }\end{array}$ \\
\hline
\end{tabular}

We can therefore propose the following set of guiding principles for HIT developers that - once implemented - would potentially optimize informal caregiver interaction:

1. Reinforce dialog, communication and coordination. ICGs place critical value on continuous communication with primary care providers and depend on HIT tools to reinforce their communication within the healthcare organization. HIT tools should enable ICGs to receive recommendations, guidance and endorsement to sources of caregiving information in the early stages.

2. Provide access to data on the patient, understanding the course of disease and knowledge of treatment information. Online availability of data sources have shortened the physical distance between the source of information and the ICG, improving CG effectiveness. This enabled continued and easy access to consolidated health information about the patient. their care professionals contact information and care-related goals. Knowledge of important treatment information improves interaction between caregivers and the understanding of the course of the disease.

3. Provide access to HIT tools that are easy to use. ICGs expect HIT tools to be easy to use whereby navigation ought to provide access to information quickly and easily. Easy-to-use HIT tools provide fast, easy access to information, incorporating the use of memory aids, visual aids and easy-to-read displays.

4. Reduce the burden of ICT literacy on the caregiver to reduce chances of error. Well-designed assisted literacy resources require little training, easy access to disease information and to online support, helpdesk, etc. help lessen risk of errors. Designers of HIT ought to minimize the pressure on ICGs related to using, checking and interpreting equipment features. The use of familiar language and simple, easy-to-understand interfaces reduce risk to care recipient (e.g. lessening prescription errors by providing tools for prescription aid).

5. Provide features to reduce CGs anxiety for caregiver effectiveness. Provide features to reduce ICG anxiety and improve ICG's coping ability in order to improve the effectiveness of CGs, i.e. ICGs must understand the specific intent of the software (or device) and gain a certain familiarity with it in a short time.

6. Provide appropriate security and privacy: Technological data monitoring maybe perceived as invasion of privacy. Users must be able to deactivate their own data transmission whenever they want.

7. Provide features for transparent information flow between formal and informal CGs. Provide secure messaging for communication among the care team. This will enable working ICGs to access information, receive support from professional CG and network transparently. Adequate training and encouragement to 
motivate family carers to use technology-based support services would need to be bundled with the solution provided. In order to minimize tension among the care team, workflow clarity is a vital component for role definition and understanding for transparency in information flow between formal and informal caregivers.

8. Provide features for patient engagement to reduce challenges of security and privacy. Putting the patient in control of their health data privacy through engagement practices, enabled by secured portals, bring the control of who can have access to patient data.

\section{Concluding Remarks}

This research was driven by the belief that the ICG is an integral part of the healthcare ecosystem, i.e., that the ICGs are not 'additional' ICT consumers but "subjects bound into the systems as necessary functional components" [54: 169].

The study turns its attention to the needs of informal carers $[18,52]$, whose centrality emerges especially in those areas where - due to patient's health conditions - the service recipients cannot themselves act as co-producers, and supports the usercentered design principles (UCD) developed by earlier IT studies on the learnability of use of a tool, system or device [53]. Given that premise, what are the basic guidelines for the design of applications more tailored to the needs and experience of ICGs?

Our paper answers this question through the recommendation of the following basic key design principles. These principles concern:

1. Features to reinforce dialog, communication and coordination between the patient and formal, informal caregivers;

2. Access to data on the patient, for the understanding the course of disease and access to knowledge on treatment information;

3. Access to HIT tools that are easy to use;

4. Features for reducing the burden of ICT literacy on the caregiver;

5. Features to reduce CGs anxiety for caregiver effectiveness;

6. Features for appropriate security and privacy;

7. Features for transparent information flow between formal and informal CGs;

8. Features for patient engagement to reduce challenges of security and privacy.

\section{- Contribution}

Our work brings a valuable contribution to the current literature that focuses on value co-creation among professionals in healthcare service [60]. While healthcare is one of the most important areas that can greatly benefit from the implementation and use of IT systems [50: 143], the extant research focuses far more on the information needs of the healthcare professionals than those of the actual patients, their informal caregivers and the wider public. The study's findings highlight the opportunities created by HIT to engage and enable ICGs. It is evident in the literature that the effective outcomes of such engagement are impossible to predict because these vary according to the differ- 
ent contingencies and interactions with other preexisting tools, norms and practices [18].

The use of the DART lens has provided an effective means for plotting the informal caregivers' interactions with the healthcare ecosystem. Drawing on concepts generated by the literature review has enabled the authors to propose a set of principles that categorizes the ICGs' needs, and hopefully, would be useful to guide both research and practice in the development of better-aligned HIT solutions.

In practice, "systems design is typically guided by the providers' perception of patients' information needs, rather than by actual needs assessment" [51:476]. The development of HIT that promotes effective interaction ought to be founded on principles that enhance dialog between formal and informal caregivers, facilitate access to data by informal caregivers, provide features for risk mitigation and capitalizes on transparency of information flows between formal and informal CGs.

Effective interactions facilitate all participants in the service ecosystem to co-create inimitable values and experiences [23] where formal care providers, ICGs and patients, participate in the value realization (quality of care).

\section{- $\quad$ Limitations}

Clearly, the preliminary principles outlined here need to be further refined and corroborated. For example, future research could explore the highly contextualized features [55] of HIT ecosystems. What works in a more or less centrally organized and fully public health system (e.g., Europe) might not work for a decentralized, marketoriented health system (e.g., United States). Economic principles and political decisions determine if a technology gets onto the market, if it is affordable and accessible also for informal caregivers.

The proposed principles are by no means exhaustive. Nevertheless, three aspects promise to be particularly instructive for the goals of the paper. First, at a macro level, the set of principles can serve to organize and promote synthesis across research findings, studies, and settings using consistent language and terminology to further stimulate conceptual development.

Second, the software developers can use the eight guiding principles to better align their solutions to the ICG practice, thus enhancing the quality of care in both nonclinical settings and the healthcare ecosystem.

Third and last, the set of principles supports the exploration of essential HIT evaluation issues to better grasp what works, where and how for the informal caregivers.

In conclusion, the paper extends prior work on user-centered design principles on usability conditions of HIT applications [58, 59], and adds to the emerging stream of research on informal caregiving to strengthen our understanding of the role of HIT as a key resource for the development of a true patient-centered health care system.

\section{- Compliance with Ethical Standards}

The authors declared no potential conflict of interest with respect to the publication of this article, and did not receive any specific grant from funding agencies in the public, commercial, or not-for-profit sectors. 


\section{References}

1. Payton, F.C., Pare, G., Le Rouge, C.M., Reddy, M.: Health care IT: process, people, patients and interdisciplinary considerations, Journal of the Association for Information Systems, 2011, 12, (Special Issue), i-xiii

2. Burns, L.R., Pauly, M.V.: 'Accountable Care Organizations May Have Difficulty Avoiding the Failures of Integrated Delivery Networks of the 1990s', Health Affairs, 2012, 31, (11)

3. Lehoux, P.: 'Patients' perspectives on high-tech home care: a qualitative inquiry into the user-friendliness of four technologies', BMC Health Serv Res, 2004, 4, (1), 1-9

4. Sheikh, A., Sood, H.S., Bates, D.W.: 'Leveraging health information technology to achieve the "triple aim" of healthcare reform', J Am Med Inform Assoc, 2015, 22, (4), 849-856

5. O'Toole, M.S., Zachariae, R., Renna, M.E., Mennin, D.S., Applebaum, A.: 'Cognitive behavioral therapies for informal caregivers of patients with cancer and cancer survivors: a systematic review and meta-analysis', Psychooncology, 2016, 1-10

6. Mitchell, M.M., Robinson, A.C., Wolff, J.L., Knowlton, A.R.: Perceived mental health status of drug users with HIV: Concordance between caregivers and care recipient reports and associations with caregiving burden and reciprocity, AIDS Behav 2014, 18, (6), 1103-1113

7. Batsch, N.L., Mittelman, M.S.: 'World Alzheimer Report 2012', Overcoming the stigma of dementia. Alzheimer's Disease International http://www. alz. org/documents_custom/world_report_2012_final.pdf, 2012

8. Woodford, J., Farrand, P., Watkins, E.R., Richards, D.A., Llewellyn, D.J.: Supported cognitive-behavioural self-help versus treatment-as-usual for depressed informal carers of stroke survivors, Trials, 2014, 15, (1), 1-10

9. Giordano, A., Cimino, V., Campanella, A., Morone, G., Fusco, A., Farinotti, M., Palmisano, L., Confalonieri, P., Lugaresi, A., Grasso, M.G.: Low quality of life and psychological wellbeing contrast with moderate perceived burden in carers of people with severe multiple sclerosis, J Neurol Sci, 2016, 366, 139-145

10. Paraponaris, A., Davin, B., Verger, P.: Formal and informal care for disabled elderly living in the community, Eur J Health Econ, 2012, 13, (3), 327-336

11. Milligan, C., Roberts, C., Mort, M.: Telecare and older people: who cares where?, Soc Sci Med, 2011, 72, (3), 347-354

12. Peterson, K., Hahn, H., Lee, A.J., Madison, C.A., Atri, A.: 'In the Information Age, do dementia caregivers get the information they need?', BMC Geriatrics, 2016, 16, (164), 179-187

13. Sorrentino, M., De Marco, M., Rossignoli, C.: 'Health Care Co-production: Co-creation of Value in Flexible Boundary Spheres', in Borangiu, T., Dragoicea, M., and Nóvoa, H. (Eds.): 'Exploring Services Science, IESS 2016' (Springer, Heidelberg 2016), 649-659

14. Lundberg, S.: The results from a two-year case study of an information and communication technology support system for family caregivers, Disabil Rehabil Assist Technol, 2014, 9, (4), 353-358 
15. Adler-Milstein, J., Embi, P.J., Middleton, B., Sarkar, I.N., Smith, J.: Crossing the health IT chasm: considerations and policy recommendations to overcome current challenges and enable value-based care, J Am Med Inform Assoc, 2017. 1-8

16. De Angelis, G., Davies, B., King, J., McEwan, J., Cavallo, S., Loew, L., Wells, G.A., Brosseau, L.: Information and Communication Technologies for the Dissemination of Clinical Practice Guidelines to Health Professionals: A Systematic Review, JMIR Med Educ, 2016, 2, (2), 1-19

17. Hillestad, R., \& Bigelow, J. H. (2005). Health information technology: can HIT lower costs and improve quality. RB-9136.

18. Alzougool, B., Chang, S., Gray, K.: Modeling the information needs of informal carers. Proc. ACIS 2007, 5-7 Dec 2007

19. Barrett, J., Davidson, E., Prabhu, J., Vargo, S.L.: Service Innovation in the Digital Age: Key Contribution and Future Directions, MIS Quarterly, 2015, 39, (1), 135-154

20. Vargo, S.L., Lusch, R.F.: It's all B2B... and beyond, Industrial marketing management, 2011, 40, (2), 181-187

21. Sorrentino, M., Badr, N. G., \& De Marco, M. (2017, May). Healthcare and the Cocreation of Value: Qualifying the Service Roles of Informal Caregivers. In International Conference on Exploring Services Science (pp. 76-86). Springer, Cham

22. Lee, T.W.: Using Qualitative Methods in Organizational Research (Sage, 1999)

23. Prahalad, C.K., Ramaswamy, V.: Co-creation experiences: The next practice in value creation, Journal of interactive marketing, 2004, 18, (3), 5-14

24. Honka, A., Kaipainen, K., Hietala, H., Saranummi, N.: Rethinking Health: ICTEnabled Services to Empower People to Manage Their Health, IEEE Rev Biomed Eng, 2011, 4, 119-139

25. Sowa, J.F.: Top-level ontological categories, Int J Hum Comput Stud, 1995, 43, (5-6), 669-685

26. Palm, E.: Who cares? Moral obligations in formal and informal care provision in the light of ICT-based home care, Health Care Anal, 2013, 21, (2), 171-188

27. Matthew-Maich, N., Harris, L., Ploeg, J., Markle-Reid, M., Valaitis, R., Ibrahim, S., Gafni, A., Isaacs, S.: Designing, Implementing, and Evaluating Mobile Health Technologies for Managing Chronic Conditions in Older Adults, JMIR mHealth and uHealth, 2016, 4, (2), 1-18

28. Robben, S.H., Perry, M., Huisjes, M., van Nieuwenhuijzen, L., Schers, H.J., van Weel, C., Rikkert, M.G.O., van Achterberg, T., Heinen, M.M., Melis, R.J.: Implementation of an innovative web-based conference table for community-dwelling frail older people, their informal caregivers and professionals, BMC Health Serv Res, 2012, 12, (1), 251263

29. Eccles, A.: The complexities of technology-based care. Telecare as perceived by care practitioners, Issues in Social Science, 2013, 1, (1), 1-20

30. Weinberg, D.B., Lusenhop, W., Gittell, J.H., Kautz, C.M.: Coordination between formal providers and informal caregivers, Health Care Manage Rev 2007, 32, (2), 140149

31. Greenhalgh, T., Stones, R.: Theorising big IT programmes in healthcare: strong structuration theory meets actor-network theory, Soc Sci Med, 2010, 70, 1285-1294 
32. Gentles, S.J., Lokker, C., McKibbon, K.A.: Health information technology to facilitate communication involving health care providers, caregivers, and pediatric patients: a scoping review, J Med Internet Res, 2010, 12, (2), 1-17

33. Torp, S., Hanson, E., Hauge, S., Ulstein, I., Magnusson, L.: A pilot study of how information and communication technology may contribute to health promotion among elderly spousal carers in Norway, Health Soc Care Community, 2008, 16, (1), 75-85

34. Garcia, C.H., Espinoza, S.E., Lichtenstein, M., Hazuda, H.P.: Health literacy associations between Hispanic elderly patients and their caregivers, J Health Commun, 2013, 18, (sup1), 256-272

35. Lum, J.: Informal Caregiving, In Focus Backgrounder, 2011, 1-11

36. Duarte, J., and Guerra, A.: User-centered healthcare design, Procedia Computer Science, 2012, 14, 189-197

37. Egan, M., Bérubé, D., Racine, G., Leonard, C., Rochon, E.: Methods to enhance verbal communication between individuals with Alzheimer's disease and their formal and informal caregivers, Int J Alzheimers Dis, 2010, 2010

38. Cristancho-Lacroix, V., Moulin, F., Wrobel, J., Batrancourt, B., Plichart, M., De Rotrou, J., Cantegreil-Kallen, I., and Rigaud, A.-S.: A web-based program for informal caregivers of persons with Alzheimer's disease: an iterative user-centered design, JMIR research protocols, 2014, 3, (3), e46

39. Madara Marasinghe, K.: Assistive technologies in reducing caregiver burden among informal caregivers of older adults: a systematic review, Disabil Rehabil Assist Technol, 2016, 11, (5), 353-360

40. Gilliard, J., Hagen, I.: Enabling Technologies for People with Dementia: Cross-national analysis report' (Enable, 2004)

41. Lopez-Hartmann, M., Wens, J., Verhoeven, V., Remmen, R.: The effect of caregiver support interventions for informal caregivers of community-dwelling frail elderly: a systematic review, Int J Integr Care, 2012, 12, (5), 133

42. Stowe, S., Harding, S.: Telecare, telehealth and telemedicine, Eur Geriatr Med, 2010, 1, (3), 193-197

43. Lu, Y.-C., Xiao, Y., Sears, A., Jacko, J.A.: A review and a framework of handheld computer adoption in healthcare, Int J Med Inform, 2005, 74, (5), 409-422

44. Hamine, S., Gerth-Guyette, E., Faulx, D., Green, B.B., Ginsburg, A.S.: Impact of mHealth chronic disease management on treatment adherence and patient outcomes: a systematic review, J Med Internet Res, 2015, 17, (2), 1-15

45. Andersson, S., Erlingsson, C., Magnusson, L., Hanson, E.: The experiences of working carers of older people regarding access to a web-based family care support network offered by a municipality, Scand J Caring Sci, 2016

46. Van Durme, T., Macq, J., Anthierens, S., Symons, L., Schmitz, O., Paulus, D., Van den Heede, K., Remmen, R.: Stakeholders' perception on the organization of chronic care: a SWOT analysis to draft avenues for health care reforms, BMC Health Serv Res, 2014, $14,(1), 179$

47 Blusi, M., Asplund, K., Jong, M.: Older family carers in rural areas: experiences from using caregiver support services based on Information and Communication Technology (ICT), Eur J Ageing, 2013, 10, (3), 191-199 
48. Kaplan, B., Maxwell, J.A.: 'Qualitative research methods for evaluating computer information systems': 'Evaluating the organizational impact of healthcare information systems' (Springer, 2005), 30-55

49. Bowen, G.A.: Naturalistic inquiry and the saturation concept: a research note, Qualitative research, 2008, 8, (1), 137-152

50. Venkatraman, S., Bala, H., Venkatesh, V., Bates, J.: Six strategies for electronic medical records systems, Commun. ACM, 2008, 51, (11), 140-144

51. Keselman, A., Logan, R., Smith, C.A., Leroy, G., Zeng-Treitler, Q.: Developing informatics tools and strategies for consumer-centered health communication, J Am Med Inform Assoc, 2008, 15, (4), 473-483

52. Nguyen, L., Evans, S., Wilde, W., Shanks, G.: 'Information needs in community aged care. Proc. PACIS 2011

53. Grudin, J.: Utility and usability: research issues and development contexts, Interacting with computers, 1992, 4, (2), 209-217

54. Ekbia, H., Nardi, B.A.: Inverse instrumentality: how technologies objectify patients and players, in Leonardi, P.M., Nardi, B.A., and Kallinikos, J. (Eds.): 'Materiality and organizing' (Oxford Univ Press, 2012), 157-176

55. Mettler, T.: Contextualizing a professional social network for health care: Experiences from an action design research study, Information Systems Journal, 2017

56. Walker, J., Darer, J.D., Elmore, J.G., Delbanco, T.: The road toward fully transparent medical records, N Engl J Med, 2014, 370, (1), 6-8

57. Lum, J., Hawkins, L., Ying, A.: Informal Caregiving and LGBT Communities (Canadian Research Network for Care in the Community, 2011)

58. Wright, P., \& McCarthy, J.: Experience-centered design: designers, users, and communities in dialogue. Synthesis Lectures on Human-Centered Informatics, 2010, $3(1), 1-123$

59. Nielsen, Jakob. "Enhancing the explanatory power of usability heuristics." Proceedings of the SIGCHI conference on Human Factors in Computing Systems. ACM, 1994

60. Zhang, L., Tong, H., Demirel, H. O., Duffy, V. G., Yih, Y., \& Bidassie, B. (2015). A practical model of value co-creation in healthcare service. Procedia Manufacturing, 3, 200-207. 